\title{
Steroid Injection Versus Open Surgery in the Treatment of De Quervain's Tenosynovitis
}

\author{
(1) Erdinç Acar ${ }^{1}$, (1) Recep Memik ${ }^{2}$
}

1Department of Orthopedics and Traumatology, Konya Necmettin Erbakan University Meram Faculty of Medicine, Hand and Upper Extremity Surgery Division, Konya, Turkey

2Department of Orthopedics and Traumatology, Konya Necmettin Erbakan University Meram Faculty of Medicine, Konya, Turkey

\begin{abstract}
Aim: This study aimed to compare steroid injection and open surgery in the treatment of De Quervain's tenosynovitis.

Materials and Methods: Between January 2013 and April 2015, a total of 82 patients (65 females, 17 males; mean age=40.3 years; range, 20 to 71 years) who were admitted were included retrospectively. The patients were assigned into two groups, including group I undergoing open surgery, and group II receiving steroid injections. The rates of recurrence and satisfaction were evaluated. The patients undergoing surgery were also evaluated for the wound site infection, nerve injury, wound opening, and limited range of motions of the joints. The patients receiving steroid injections were evaluated for subcutaneous atrophy, fat necrosis, weakening or rupture of tendons, and depigmentation.

Results: The mean follow-up was 12 months (range: 6 to 22). Recurrence occurred in eight patients (20\%) in the steroid injection group; however, no recurrence was seen in patients undergoing open surgery. Satisfactory or very satisfactory results were achieved in all patients in the surgery group $(p=0.04)$. There were no complications in both groups.

Conclusion: Although steroid injection is a therapeutic option in De Quervain's tenosynovitis, open surgery appears to be a more beneficial method with relatively low recurrence and complication rates.
\end{abstract}

Keywords: De Quervain's tenosynovitis, open surgery, steroid injection

\section{Introduction}

De Quervain's tenosynovitis is one of the most common forms of stenosing tenosynovitis encountered by hand surgeons. This tenosynovitis was first described by De Quervain (1). De Quervain's tenosynovitis causes radial wrist pain that increases with activity (2). Steroid injection into the tendon sheath is a standard method as a primary treatment in uncomplicated cases (3). Although steroid injection is common, complications such as subcutaneous atrophy, fat necrosis, weakening or rupture of tendons, and depigmentation have been reported after this treatment regimen (4-7). A surgical release that provides a precise and permanent solution in most cases is considered for steroid-refractory patients and for patients whose complaints last over six months $(8,9)$. Since the rate of recurrence and complication is lower after surgical treatment, currently, it has been widely used.

In the present study, we aimed to evaluate the efficacy of open surgery versus steroid injection in patients with De Quervain's tenosynovitis.

\section{Materials and Methods}

A total of 82 patients (65 females, 17 males) who were admitted between January 2013 and April 2015 were homogeneously divided into two equal groups. There were 42 patients (35 females, 7 males) in the first group and 40 patients (30 females, 
10 males) in the second group. In the first group, open surgery was performed. In the second group, steroid injection was performed. An informed consent form was obtained from each patient. The study was approved by the Necmettin Erbakan University Meram Faculty of Medicine Ethics Committee and was conducted in accordance with the principles of the Declaration of Helsinki (protocol no: 2017/1018).

The patients were diagnosed by medical history and positive Finkelstein test results performed during physical examination. Finkelstein test was performed to trigger the pain that occurred by the ulnar deviation of the wrist, while the thumb was being locked in the palm, and it is one of the diagnostic criteria of the disease $(10,11)$. An X-ray was obtained from each patient to differentiate arthritis of the thumb, metacarpophalangeal joints, and scaphoid-trapezium-trapezoid joints, arthrosis of radiocarpal and intercarpal joints, and fracture of the scaphoid. Extensor pollicis brevis (EPB) entrapment test was performed to the patients with recurrent disease after steroid injection. The sensitivity of the EPB entrapment test has been reported to be $81 \%$ in identifying patients having a separate septum for the EPB tendon with the failure of corticosteroid injection (12). The test consists of two parts. First, the patient is asked to bring the metacarpophalangeal joint to the forced extension. Second, the carpometacarpal joint of the patient is abducted by the examiner in a stretched manner. Pain during the second part of the test suggests that there may be a separate compartment for the EPB (12).

All open surgeries were performed under regional intravenous anesthesia. Tourniquet was applied to all patients to identify the sensory branches of the radial nerve carefully. During surgery, an oblique or transverse skin incision was performed over the first dorsal compartment, about 1-cm proximal to the radial styloid process. To identify the sensory branches of radial nerve passing obliquely over the compartment, deep layers of the skin were gently dissected longitudinally. After the skin and subcutaneous tissue were dissected, the annular ligament was finely incised with a scalpel. The release of the tendons of abductor pollicis longus (APL) and EPB in the proximal and distal was confirmed (Figure 1). In the case of another septal formation, it was also released. After hemostasis, the skin was anatomically closed with 4/0 prolene sutures. The wound was dressed, and a bulky bandage was applied. In the early postoperative period (on day 1), the dressings of the patients were made smaller to allow wrist movements easily, and serious training was given to the patients and their relatives about the frequent mobilization to maintain the range of motion of the joints completely. In this training, it was emphasized to bring the wrist to full flexion-extension with the support of analgesics, particularly in the early postoperative period.
In patients who underwent steroid injection, the injection was performed using a dorsoradial approach as a standard procedure. First, radial styloid was found, steroid injection was performed to the distal of the APL and EPB tendons, with a 45-degree angle towards the radial styloid (Figure 2). During injection, the presence of resistance indicated that it was on the tendon; therefore, the needle was withdrawn and injected around the tendon. After injection, active/passive extension and flexion movements were initiated.

In the postoperative period, a non-steroidal anti-inflammatory drug and oral antibiotic (amoxicillin/clavulanate potassium 1 g twice a day) were prescribed for one week. Dressings were changed every three days. Sutures were removed at the postoperative second week, and the patients were examined at 6 , 12, 24 weeks, and one year. The recurrence rate and satisfaction after intervention were investigated in both groups using the 10-point Visual Analogue scale. The overall satisfaction rates were evaluated according to the scores of 10:1-3 very dissatisfied; 4-5 dissatisfied; 6-7 satisfied; $\geq 8$ very satisfied.

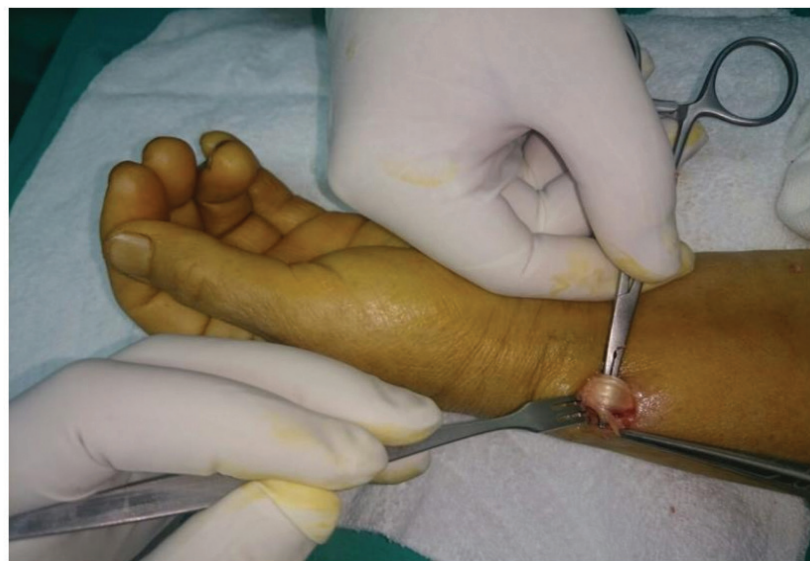

Figure 1. Release of the first dorsal extensor compartment

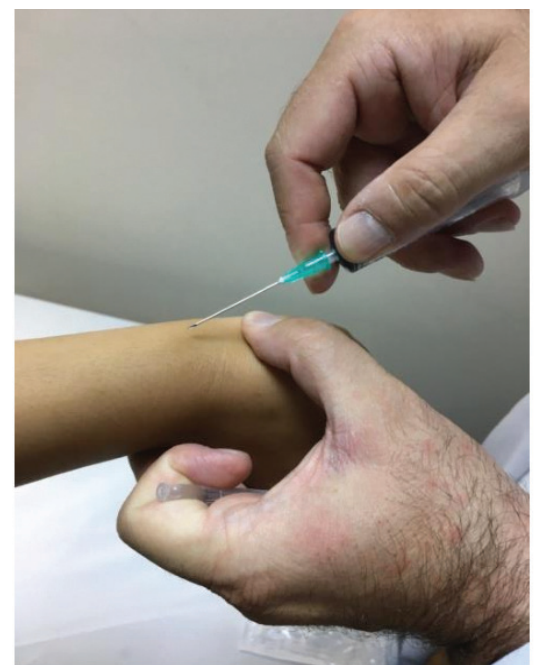

Figure 2. Steroid injection 
Complications such as wound site infection, nerve injury, wound opening, and limited range of motions of the joints were evaluated in operated patients. Also, complications such as subcutaneous atrophy, fat necrosis, weakening or rupture of tendons, and depigmentation were evaluated in patients who underwent steroid injection.

\section{Statistical Analysis}

Statistical analysis was performed using the Number Cruncher Statistical System (NCSS) 2007 and Power Analysis, and Sample Size 2008 statistical software (NCSS, LLC; Kaysville, Utah, USA) program was used for statistical analysis. Descriptive data were primarily presented as means. A p-value of $<0.05$ was considered statistically significant.

\section{Results}

The mean age of the patients was 40.3 years (range: 20 to 71). Demographic and clinical data of the patients are presented in the table (Table 1).

The mean follow-up was 12 months (range: 6 to 22). In the steroid injection group, recurrence was seen in eight patients (20\%). Also, the EPB entrapment test was positive in eight patients with recurrence following steroid injection.

In our study, the Trigger thumb was also present in two patients who underwent surgery. Surgery of the trigger thumb was performed in the same session. No recurrence was observed in the surgery group. No severe complication occurred in any patient. Open surgery was performed in patients with recurrence. These patients did not recur after surgery.
All of the patients who underwent surgery indicated that they were satisfied or very satisfied with the surgical treatment $(p=0.04)$. Ten patients who underwent steroid injection indicated that they were dissatisfied or very dissatisfied. Two patients reported that they were dissatisfied due to severe pain after injection, although their complaints resolved. Eight patients were very dissatisfied due to recurrence (Table 2 ).

\section{Discussion}

There are many case series reporting that De Quervain's tenosynovitis is common, particularly in females, between the third and fifth decades of life. Although some reports have shown that it most commonly involves the dominant hand, the relationship with this disease has not been fully clarified yet. However, the fact that the disease is seen less frequently in males and that the dominant hand is not related to this condition are the main reasons for uncertainty in the etiology of this disease (13). In our study, consistent with previous reports in the literature, De Quervain's tenosynovitis was more common in female patients, and it most commonly affected the dominant hand. Also, the diagnosis of De Quervain's tenosynovitis is made radiographically. Ultrasonographic (USG) examinations and magnetic resonance imaging (MRI) can also be performed to identify anatomic variations in patients and to confirm the diagnosis $(14,15)$. In our patients, USG and MRI were not performed, and the diagnosis was only based on radiographic findings with X-ray.

Many authors have suggested that the steroid injection into the tendon sheaths as the first-line treatment in De Quervain's

Table 1. Demographic and clinical data of patients

\begin{tabular}{lll}
\hline & Open surgery $(\mathbf{n}=\mathbf{4 2})$ & Steroid injection $(\mathbf{n}=\mathbf{4 0})$ \\
\hline Age, mean (range) & $40(20-70)$ & $41(21-71)$ \\
\hline Sex, number (\%) & & $30(75)$ \\
Female & $35(83.3)$ & $10(25)$ \\
Male & $7(16.7)$ & \\
Side, number & & $34 / 6$ \\
Right/Left & $32 / 10$ & $35 / 5$ \\
Dominant/Non-dominant & $36 / 6$ & \\
\hline
\end{tabular}

Table 2. Patient satisfactiona

\begin{tabular}{llll}
\hline Satisfaction Rating (score distributiona) & Open surgery number (\%) & Steroid injection number (\%) & p-value \\
\hline Very satisfied (8 to 10) & $38(90.4)$ & $10(25)$ & $20(50)$ \\
\hline Satisfied (6 to 7) & $4(9.6)$ & $2(5)$ & 0.04 \\
\hline Dissatisfied (4 to 5) & $0(0)$ & $8(20)$ & 0.04 \\
\hline Very dissatisfied (1 to 3) & $0(0)$ & & 0.04 \\
\hline Patient satisfaction was measured by a 10-point Visual Analogue Scale (VAS) & 0.04 \\
\hline
\end{tabular}


tenosynovitis is effective. In a study conducted by Harvey et al. (16), corticosteroids were administered to the patients once or twice, and success was achieved in $80 \%$ of the patients after a nine-year follow-up period. In the study mentioned above, 10 of 11 patients in whom treatment failed, APL and EPB tendons were found to be in separate compartments during surgical release. In another study, Witt et al. (17) reported that they achieved improvement in $62 \%$ of the patients after steroid injection. In a study in which patients were followed to three years, only $12 \%$ of the patients underwent surgery after the injection (18). Overall, these study findings indicate that the tendons are in separate compartments or showed separate septations in surgical patients in whom steroid injection failed (19-22). In our study, an improvement was achieved in $80 \%$ of the patients in the steroid injection group, and $20 \%$ of them needed surgery. This finding is consistent with the literature. The EPB entrapment test was also positive in patients with recurrence, and open surgery was performed to these patients, and no recurrence was seen (12).

In the literature, it has been reported that complications may occur, such as subcutaneous atrophy, fat necrosis, weakening or rupture of tendons, and depigmentation following steroid injection for the treatment of De Quervain's tenosynovitis (4-7). In our study, no complications were seen in either group.

Furthermore, some authors have suggested that steroid injection is a part of treatment for De Quervain's tenosynovitis; however, surgical intervention should be done when the non-surgical treatments are inadequate or when the patient is expecting a rapid and precise outcome (23). In a study by Lee et al. (24), 33 patients with De Quervain's tenosynovitis underwent open surgery, and they reported that the results were very good after a six-year follow-up. Surgically, a transverse incision was used, and no complications were observed. Although the results are similar to our study, the length of follow-up time was reported in the literature.

Bouras et al. (25) reported in their series of 20 cases that the outcomes were close to perfect after open surgery, and they showed that complication was not seen using a longitudinal incision. Abrisham et al. (26) also reported that open surgery was superior, and a longitudinal incision was better than transverse incision after a five-year follow-up period. In our study, an oblique or transverse incision was used, and no complications were observed. Therefore, we suggest that, although the direction of surgical incision is critical, the attention of the surgeon also affects surgical success.

Complications such as wound site infection, nerve injury, wound opening, and limitation of range of motion of the joint can be seen following open surgery (27). Volar subluxation of tendons as a rare complication has also been reported in the literature. Altay et al. (28) performed partial excision of the extensor retinaculum during open surgery to avoid subluxation complications. They found that the results were consistent with the complete excision of the retinaculum, and no complications were observed. In our study, complete excision was performed, and no volar tendon subluxation was observed.

\section{Study Limitations}

The implications of this study are limited by its retrospective design and the relatively small number of patients.

\section{Conclusion}

In conclusion, our study results suggest that, although steroid injection is a treatment option for De Quervain's tenosynovitis, open surgery seems to be a more useful method with relatively low recurrence and complication rates.

\section{Ethics}

Ethics Committee Approval: The study was approved by the Necmettin Erbakan University Meram Faculty of Medicine Ethics Committee and was conducted in accordance with the principles of the Declaration of Helsinki (protocol no: 2017/1018).

Informed Consent: An informed consent form was obtained from each patient.

Peer-review: Externally peer-reviewed.

\section{Authorship Contributions}

Surgical and Medical Practice: E.A., R.M., Concept: E.A., R.M., Design: E.A., R.M., Data Collection or Processing: E.A., Analysis or Interpretation: E.A., R.M., Literature Search: E.A., Writing: E.A.

Conflict of Interest: No conflict of interest was declared by the authors.

Financial Disclosure: The authors declared that this study received no financial support.

\section{References}

1. De Quervain F. On a form of chronic tendovaginitis by Dr. Fritz de Quervain in la Chaux-de-fonds. 1895. Am J Orthop. 1997;26:641-4.

2. Stein AH, Ramsey RH, Key Ja. Stenosing tendovaginitis at the radial styloid process (DeQuervain's disease). AMA Arch Surg. 1951;63:216-28.

3. Oh JK, Messing S, Hyrien O, Hammert WC. Effectiveness of Corticosteroid Injections for Treatment of de Quervain's Tenosynovitis. Hand (NY). 2017;12:357-61

4. Ilyas AM, Ast M, Schaffer AA, Thoder J. De quervain tenosynovitis of the wrist. J Am Acad Orthop Surg. 2007;15:757-64.

5. Akram M, Shahzad ML, Farooqi FM, Irshad M, Kumar Sah R, Awais SM. Results of injection corticosteroids in treatment of De Quervain's Tenosynovitis. J Pak Med Assoc. 2014;64:30-3. 
6. Richie CA, Briner WW Jr. Corticosteroid injection for treatment of de Quervain's tenosynovitis: a pooled quantitative literature evaluation. J Am Board Fam Pract. 2003;16:102-6.

7. Wharton R, Thaya M, Eckersley R. The dangers of injecting blind: Abductor pollicis longus tendon rupture in de Quervain's disease. J Hand Surg Eur Vol. 2015;40:322-3.

8. Moore JS. De Quervain's tenosynovitis: Stenosing tenosynovitis of the first dorsal compartment. J Occup Environ Med. 1997;39:990-1002.

9. Lee ZH, Stranix JT, Anzai L, Sharma S. Surgical anatomy of the first extensor compartment: A systematic review and comparison of normal cadavers vs. De Quervain syndrome patients. J Plast Reconstr Aesthet Surg. 2017;70:12731.

10. Finkelstein $\mathrm{H}$. Stenosing tendovaginitis at the radial styloid process. J Bone Jt Surg. 1930;12:509-40.

11. Kutsumi K, Amadio PC, Zhao C, Zobitz ME, Tanaka T, An KN. Finkelstein's test: a biomechanical analysis. J Hand Surg Am. 2005;30:130-5.

12. Alexander RD, Catalano LW, Barron OA, Glickel SZ. The extensor pollicis brevis entrapment test in the treatment of de Quervain's disease. J Hand Surg Am. 2002;27:813-6.

13. Kay NR. De Quervain's disease: changing patology or changing perception? J Hand Surg Br. 2000;25:65-9.

14. Nagaoka M, Matsuzaki H, Suzuki T. Ultrasonographic examination of de Quervain's disease. J Orthop Sci. 2000;5:96-9.

15. Kamel M, Moghazy K, Eid H, Mansour R. Ultrasonographic diagnosis of de Quervain's tenosynovitis. Ann Rheum Dis. 2002;61:1034-5.

16. Harvey FJ, Harvey PM, Horsey MW. De Quervain's disease: Surgical or nonsurgical treatment. J Hand Surg Am. 1990;15:83-7.

17. Witt J, Pess G, Gelberman RH. Treatment of de Quervain tenosynovitis. A prospective study of the results of injection of steroids and immobilization in a splint. J Bone Joint Surg Am. 1991;73:219-22.

18. Rankin ME, Rankin EA. Injection therapy for management of stenosing tenosynovitis (de Quervain's disease) of the wrist. J Natl Med Assoc. 1998;90:474-6.
19. Jackson WT, Viegas SF, Coon TM, Stimpson KD, Frogameni AD, Simpson JM. Anatomical variations in the first extensor compartment of the wrist. A clinical and anatomical study. J Bone Joint Surg Am. 1986;68:923-6.

20. Kutsumi K, Amadio PC, Zhao C, Zabitz ME, An KN. Gliding resistance of the extensor pollicis brevis tendon and abductor pollicis tendon within the first dorsal compartment on fixed wrist positions. J Orthop Res 2005;23:243-8.

21. Kulthanan T, Chareonwat B. Variations in abductor pollicis longus and extensor pollicis brevis tendons in de Quervain syndrome: A surgical and anatomical study. Scand J Plast Reconstr Surg Hand Surg. 2007;41:36-8.

22. Sawaizumi T, Nanno M, Ito H. De Quervain's disease: efficacy of intra-sheath triamcinolone injection. Int Orthop 2006;31:265-8.

23. Özdemir O, Çoșkunol E, Özalp T. De Quervain tenosinovitinin patolojik anatomisi ve cerrahi tedavisi. Acta Orthop Traumatol Turc. 2000;34:71-4.

24. Lee HJ, Kim PT, Aminata IW, Hong HP, Yoon JP, Jeon IH. Surgical release of the first extensor compartment for refractory de Quervain's tenosynovitis: surgical findings and functional evaluation using DASH scores. Clin Orthop Surg. 2014;6:405-9.

25. Bouras Y, El Andaloussi Y, Zaouari T, Touil N, Fnini S, Chikhaoui N, et al. Surgical treatment in De Quervain's tenosynovitis. About 20 cases. Ann Chir Plast Esthet. 2010;55:42-5.

26. Abrisham SJ, Karbasi MH, Zare J, Behnamfar Z, Tafti AD, Shishesaz B. De qeurvain tenosynovitis: clinical outcomes of surgical treatment with longitudinal and transverse incision. Oman Med J. 2011;26:91-3.

27. Alegado RB, Meals RA. An unusual complication following surgical treatment of de Quervain's disease. J Hand Surg Am. 1979;4:185-6.

28. Altay MA, Erturk C, Isikan UE. De Quervain's disease treatment using partial resection of the extensor retinaculum: A short-term results survey. Orthop Traumatol Surg Res. 2011;97:489-93. 